\title{
Sequential Procedure for Improving the Efficiency of CI Engine by Using Artificial Neural Networks
}

\author{
Balaji Ganesh Nagisetty*, Sri Hari Podala Venkata \\ Department of Mechanical Engineering, R.V. College of Engineering, Bangalore 560059, India
}

Corresponding Author Email: balajiganeshn@gmail.com

https://doi.org/10.18280/ijht.380422

Received: 23 February 2020

Accepted: 12 September 2020

\section{Keywords:}

neural networks, MATLAB, Emissions, CI

Engines, inlet manifolds

\begin{abstract}
This work provides a sequential approach to improve efficiency of Combustion Ignition engines which involves both performance and emissions by using the artificial neural network (ANN). In recent years continuous work is going on for improving the output and reducing the emissions especially for Combustion Ignition engines which are mostly used for transportation purposes. In view of the above, the experimental data of a four stroke Combustion Ignition engine is taken as reference. However, the experimental data is split into three categories as input data, target data and output data in neural networks. All these data are trained using neural network toolbar in MATLAB with ten hidden layers by which error deviation are calculated, in order to reduce error deviation between neural network and experimental values, design of inlet manifolds is varied and performance parameters along with emissions is calculated and compared with neural network values. The results showed minimum error over the emission and performance parameters of CI engines from the manifold designs and ANN model. These results provide a sequential approach to improve efficiency of Combustion Ignition engines with the help of neural networks.
\end{abstract}

\section{INTRODUCTION}

Diesel engine is most widely used in transportation purposes that is operative on a vast variety of natural operating conditions. Despite of its merits one of the main concerns for diesel engines are its emissions that causes adverse effects to environment. The main constituents of the pollution are soot formation which includes unburnt hydro carbons, carbon monoxide and addition to its NOX plays a vital role [1]. The emissions are reduced by enhancing correct fuel and air being mixed inside the engine cylinder that can be achieved by providing some motion (secondary) to inside air of the cylinder under different designing of intaking a manifold which is termed as swirl.

The swirl is produced by providing helical threads, spiral threads with different pitches and orientations results improved performance and lesser emissions [2-6]. In addition to previous methods design of piston is also varied to provide swirl by providing tangential holes in the piston with varies dimensions and by varying $\mathrm{d} / \mathrm{D}$ ratio which results in optimum configuration with minimum emissions [7-8]. Along with swirl turbulence also has some prominent role in proper fuel and air mixings which leads to proper combustion in turns improves performance of engine by reducing emissions. Intake manifold is modified with throat size by providing frustum of cones with depth of cut on the piston reduces fuel consumption and emissions [9]. The inlet velocity of air also affects the turbulence of air to achieve this converging nozzle, convergent- divergent nozzle manifolds are replaced with normal manifolds in which better results are obtained at certain designs conditions [10-11]. The modeling and analysis of incoming air with helical threads by varying pitches, incoming velocity of air along with dynamic characteristics of intake system is analyzed in CFD got optimum results [12-14].

ANN is an effective tool used to optimize the engine characteristics without conducting experiment on experimental set up. ANN is optimizing technique where war is won without directly involving in it. ANN along with back propagation algorithm predict the performance parameters and emissions of a 2-stroke engine with bio lubricants using a multilayer perception neural network with a 3-25-8 set of input layer, hidden layer and output layer where the results are within the acceptable limits [15]. The performance of diesel engine by varying blends is correlated using ANN where mean square error between output and simulated values is within acceptable range [16]. The performance and emission characteristics are predicted by using modelling done with the help of ANN on an engine operated using hydrogen as a dual fuel and diesel as primary fuel mode having 7 different algorithms for training to be assessed and also nearly 5 transfer functions in combination where the transfer functions of hyperbolic tangent sigmoid and logarithmic sigmoid for Levenberg-Marquardt having 16 total neurons were discovered to have some best value of regression along with mean percentage error and minimum mean square error [17]

ANN is successfully applied as an alternative modeling technique type with adequate accuracy for engines ignited by sparks, fueled with the blends of alcohol and gasolines as well as bio gas [18]. ANN can be used a tool to detect the performance which helps in saving both time and costs for developing new methodologies and models for the whole performance of the engine [19]. ANN approach is used for 
mapping both the emission characteristics and the performance accurately operated on engines using dual fuel along with LPG [20]. ANN models with four differential statistical tests namely RMSE, R2, MEP and SEE are successfully examined the performance and reliability of IC engine in which all of them delivers adequate results [21]. To evaluate the engine emission characteristics MSE and Trainlm Function in ANN model are suited best in which the percentage of error for every predicted value is in between 0.01 to 0.03 [22]. ANN is applied for calibrating the spark ignition engines in certain areas for identification of the systems helping in rapid prototypes, where the multi-layer networks were utilized for identification of the system whereas in case of higher inputs single layer is used for characterization and identification of dynamic systems as the trained ANN systems could easily satisfy maximum of the modeling requirements for calibrating engine which deals with high input dimensionality by reducing calibration time [23].

Artificial Neural Network was used for predicting the vibration and noise characteristic of dual fueled engines with natural gas, where experiment is done on the diesel engines on five varying level of speeds with dual fuel along with natural gas decreases vibration and sound pressure values which are compared with ANN model where the results are in correct ranges. Further the outcomes of the Network are compared to the results of linear regression outputs and a conclusion was made that ANN helps in providing more accurate results [24]. The cyclic variability for engines fueled with diesel with blends and n-butanol are modeled using ANN, where engine is operated with ten different speeds with six blends to evaluate coefficient of variation whose best value is $3.04 \%$ at $1,200 \mathrm{rpm}$ for Blend 15 , these outcomes are required for training the ANN to predict coefficient of variation using MSE and MAPE to evaluate networks, the results obtained are correlated with the data from the experiment with overall high accuracy and R: correlation coefficient value in the range of 0.858 to 0.983 [25]. The acoustic signatures that are obtained from the engines are processed based on the signature characteristics and frequency values.

To analyze the emission from HCCI engine and its performance operated at a mechanisms of reduced valve lift using different fuels are satisfactorily performed by 3D CFD simulation and ANN-GA optimization models [26]. Optimization of DI-CI characteristics of an engine fueled using bio fuel is done through Artificial Neural Network depending on the prediction model by using trainrp, trainscg, traingdx and trainlm as four different transfer functions, where among all these functions the transfer function trainlm has lowest error percentage with highest accuracy [27]. A. Dominguez used ANN and symbolic regression under transient conditions to predict emissions from a diesel engine working on animal fat, where both the models predicted emissions similarly and it became difficult for obtaining predictive models for the particles in nucleation mode because of randomness and high variability [28]. ANN model predicted the output variables with a high-level accuracy operated on a HCCI- DI engine [29]. ANN model is developed for hydrogen enriched compressed natural gas engine gave good results [30]. F. Dedola proposed an effective methodology on using ANN to provide a detailed engine date by reducing number of experimental data in which volumetric efficiency is taken as reference [31].
This experiment instantaneously makes use of varying strategies for achieving aims of improving its performance and at the same time reducing any kind of emissions from an engine operating on diesel. The primary strategy is using ANN for which experimental data collected from the engine is given as input values in MATLAB using ANN tool bar the output values, error values are obtained by training the networks by using hidden layers as shown in Figure1.Secondly for optimizing the parameters of the engine as well as for reducing the error deviation between ANN values and experimental data, the designs of inlet manifold are varied as threaded manifold and convergent nozzle as indicated in Figures 5 and 6 . For both the designs the experiment is conducted separately on the engine as shown in Figure 3. Specifications are listed in Table 1. By varying load at rated speed and all the performance parameters are calculated by using standard mechanical formulae along with exhaust emissions are also measured.

The output values obtained by varying design of Intake manifold is again compared with ANN values and the Variation of error deviation is studied for different loads. The designing of manifold is often the critical task to study the performance parameter and emission characteristics of $\mathrm{CI}$ engine. For resolving these issues, the ANN model can be employed for describing a multi-dimensional and non-linear system. ANN predicted the output values with modified solution that are accepted widely among the automobile industries [32]. Based on the obtained data, the ANN model is employed to optimize the performance parameter. The optimized parameter is used for generating the manifold design which are evaluated for its performance and emission. Finally, the obtained outcome is compared with ANN results.

\section{METHODOLOGY}

Neural Network or Artificial Neural Network, is defined as a computational or mathematical model which is inspired from the function or/and structural aspects of biological neural network. There exists a set of artificial neurons interconnected to one-another in a group and this system then helps in processing the information with the help a of connectionist method for computations. Mostly Artificial Neural Network is defined as some adaptive type of system which can change its structure depending on the internal and external information which flows into a network at the time of learning. Modern ANNs are the non-linear statistically data modelling the ANN, normally known as the Neural Networks and are termed as a computational or mathematical model which is inspired by functional aspects or structured of the Biological NNs. In maximum of the cases Artificial Neural Networks are adaptive systems which changes their structure depending on the internal and external information which flows inside a network during or in the learning period. Modern NN are the non-linear statistical modeling of data. Both the output and input layers are normalized in a $(0,1)$ range. For achieving the best prediction in a network, much different architecture are trained and calculated by making use of an input data. For all the Artificial Neural Network Models in the present study only back propagation algorithm was used. The methodology involves a supervised technique for training where the biases and network weights were randomly initialized during the initial time of the training phase. Gradient descent rule is used for the process of error 
minimization. The input variables are engine speed, time, temperature, and load. The results used to evaluate the performance of an engine is brake power, total fuel consumption, brake thermal efficiency, mechanical efficiency, volumetric efficiency along with the emissions such as $\mathrm{CO}_{2}$, $\mathrm{CO}, \mathrm{HC}, \mathrm{O}_{2}$.

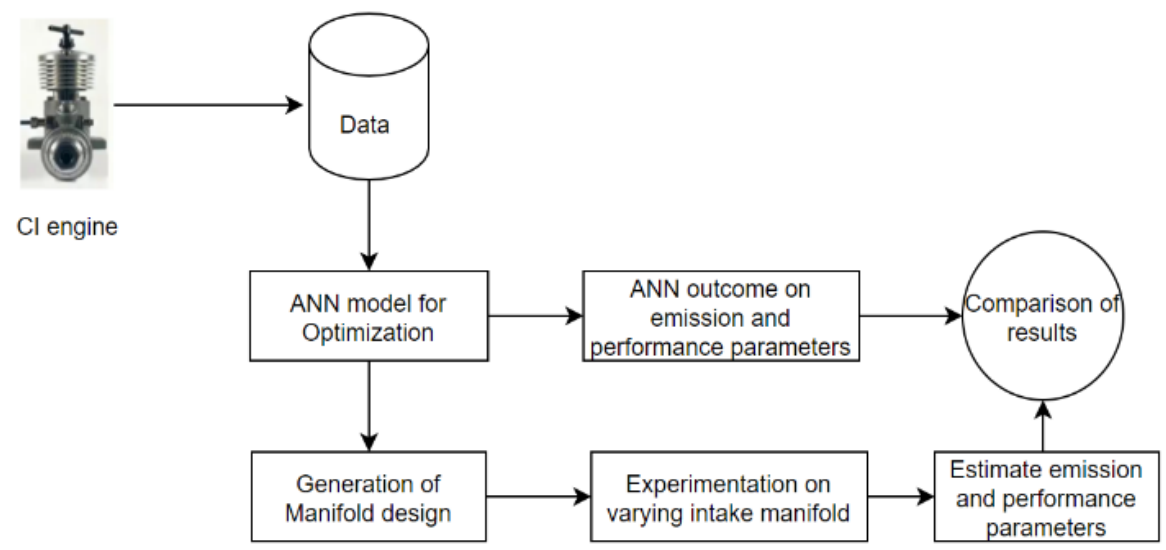

Figure 1. Detailed scheme of methodology

Testing of different algorithms were done and ultimately Levenberg-Marquardt Algorithm was chosen for this operation. MATLAB 2014a, with toolbox of neural network was used for designing the artificial neural network. The output values obtained from the neural network is compared with experimental values and error is calculated based on the error deviation the design of inlet manifold is changed as shown in Figure 1.

Total hidden layers and the number of neurons in every layer is designed as per the complexity level of the data set and the problem involved. In the present research the total number of hidden layers is taken as ten which gives accurate values. The layout of input, hidden layer, output is shown in Figure 2. For making sure every input variable offers and equal part in the functioning of ANN, the model inputs are processed before-hand and are scaled to a $(0,1)$ common range. For hidden layers the activation functions were chosen to be logic. For output layers the best suitable system was that of a linear function. Such an arrangement of functions for modeling or function approximation problems are quite common and results in better results.

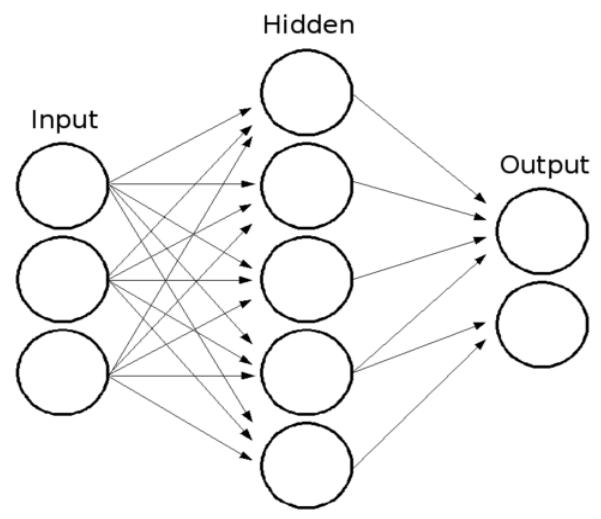

Figure 2. Multi-layer feed forward network

\subsection{Experimentation}

This method was carried out on a direct-injection singlecylinder engine fueled with diesel with a dynamometer coupled to it. Figure 3. shows schematic view of the test bed of an engine along with the measuring devices. The geometrical and mechanical specifications for test bed of engine are detailed in Table 1.

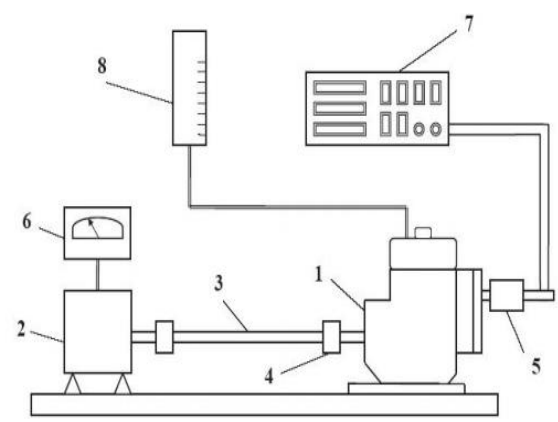

The schematic diagram of the experimental set-up. (1) Engine, (2) Dynamometer, (3) Shaft, (4) Flywheel, (5) Exhaust pipe, (6) Dynamometer control unit, (7) Gas analyzer, and (8) Fuel measurement system.

Figure 3. Schematic diagram of test rig

Table 1. Specifications of the used engine

\begin{tabular}{cc}
\hline Parameter & Specification \\
\hline Make of the engine & Kirloskar AV1 \\
\hline Bore diameter & $88 \mathrm{~mm}$ \\
\hline Stroke length & $116 \mathrm{~mm}$ \\
\hline Compression ratio & $16: 1$ \\
\hline Rated output & $5 \mathrm{HP}$ \\
\hline Temperature & $280 \mathrm{c}$ \\
\hline Number of cylinders & one \\
\hline General Details & 4-Stroke CI Engine \\
\hline Type of Cylinder & Vertical \\
\hline Cooling & Water cooled \\
\hline Rated speed & $1,500 \mathrm{rpm}$ \\
\hline
\end{tabular}

Experiments are carried out with no such structural changes required in the engine. Loading of test engine is done by varying load on the engine at constant speed. Emissions from the exhausts are estimated with the help of an Exhaust gas analyzer, and fuel burette method is used for measuring fuel consumption. Initially the data obtained from the experiments with normal manifold (Figure 4) is given as input in neural networks from which error value is calculated; 
for reducing the error deviation the design of inlet manifold is modified as depicted in Figure 5 and Figure 6.

\subsection{New manifold design}

\subsubsection{Normal manifold}

The diameter and length of the normal manifold is shown in Figure 4. The manufacturing of normal manifold was done using stainless steel as material. It connects air box to the valve of inlet of an engine as depicted in Figure 4.

\subsubsection{Threaded manifold}

In this current work, designing of the intake manifold of the Engine is slightly changes by providing helical threads into a manifold with pitch $3 \mathrm{~mm}$ are used. The performance characteristics along with emissions are verified with the modified manifold design. The manifolds were casted with appropriate dimensions. The threading is started at the inlet of the intake manifold parallel to the central axis of the manifold. This is made to guide the airflow along the threaded path which facilitates for generating swirl along the central axis of the manifold. The width of the thread is about $3 \mathrm{~mm}$ and the depth of the thread is about $3 \mathrm{~mm}$. The manifold had a core diameter of $30 \mathrm{~mm}$, taking the thread into consideration, $26 \mathrm{~mm}$ is the inner diameter and $30 \mathrm{~mm}$ is the outer diameter as shown in Figure 5.

\subsubsection{Manifold with nozzle}

The manifold has core diameter of nearly $30 \mathrm{~mm}$, nozzle with inner diameter of $15 \mathrm{~mm}$ and its outer diameter is about $29 \mathrm{~mm}$. The material used for manufacturing the nozzle is stainless steel. Nozzle dimensions were considered to calibrate the required nozzle dimensions. Manufacturing of nozzle is done with convergent length of $430 \mathrm{~mm}$ and constant length of 430mm as shown in Figure 6.

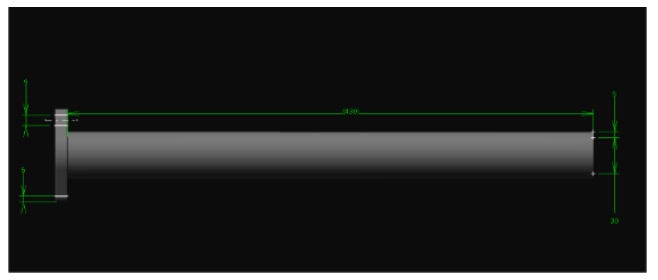

Figure 4. Normal manifold

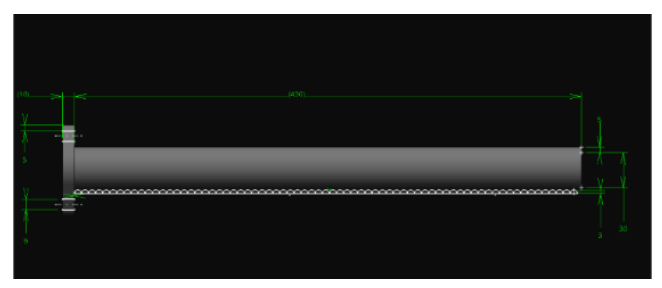

Figure 5. Threaded manifold

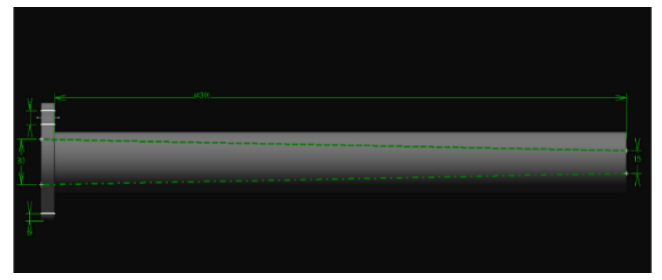

Figure 6. Convergent nozzle manifold

\section{RESULTS AND DISCUSSIONS}

From the above used method, the results are further summarized as:

From first section 3.1 the outcomes achieved using the Artificial Neural Network model for a normal manifold show that using ANN to predict TFC, BTE, volumetric efficiency, Mechanical efficiency and emissions is sufficient.

In section 3.2, outcome achieved from manifold design are compared to the ANN system. The error deviation for all the manifolds were compared to one another for best output manifold performances out of all of the cases. The error deviation is calculated as Experimental values - ANN values.

\subsection{Comparison between ANN values and Normal Manifold}

\subsubsection{Engine performance}

The comparison among the estimated outcomes with that of the results from experimental for TFC, BTE, volumetric efficiency, and Mechanical efficiency is shown in Figure7. TFC is a measure of efficiency of an engine. Where the thermal efficiency of engine brake and TFC are inversely proportional, hence lower the TFC, higher the thermal efficiency. The variation TFC and brake thermal efficiency at different loads for ANN and Normal manifold is shown in the Figure 7(a), (b). It can be seen that fuel consumption is less in ANN which increases brake thermal efficiency when compared to that of normal manifold as shown in Figure 8 . The error deviation is positive for TFC and negative for Brake thermal efficiency as shown in Figure7(b), therefore the error deviation can be decreased by changing the manifold design as shown in Figure 9(a) and (b).

Brake thermal efficiency,

$$
\eta_{\text {bth }}=\frac{\text { B.P }}{\text { Heat input }} \times 100 \%
$$

Volumetric Efficiency,

$$
\eta_{\mathrm{vol}}=\frac{\text { actual volume flow rate of air }}{\text { Theoritical Volume flow rate of air }} \times 100 \%
$$

Actual volume flow rate of air

$$
\left(\mathrm{Q}_{\mathrm{act}}\right)=\mathrm{C}_{\mathrm{d}} \times \mathrm{a} \times \sqrt{2} g h a \mathrm{~m}^{3} / \mathrm{s}
$$

where,

Co-efficient of discharge $\left(C_{d}\right)=0.62$;

$\mathrm{d}=0.02 \mathrm{~m}$

Area $(\mathrm{a})=\frac{\pi d^{2}}{4} m^{2}$.

Volumetric efficiency is stated as the breathing capacity of an engine which depends on the atmospheric conditions. Since the atmospheric temperature remains as constant for most of the time during experimentation and engine is operated at rated speed, the volumetric efficiency remains as constant for Normal manifold but it is less than ANN value, the error deviation is negative as shown in Figure 9(c), the volumetric efficiency is increased by changing the design of intake manifold as shown in Figure 10(b).

Mechanical efficiency can be defined as a ratio brake and indicated power, brake power remains constant for all 
manifold designs at a given particular load as engine is operated at constant speed and constant torque. Indicated power is the power which is available at the piston top. Mathematically indicated power is sum of brake power and friction power. Brake power is calculated from standard mechanical formulae and friction power is measured by Wilson line method, by using the mathematical formula indicated power is measured and finally mechanical efficiency is calculated at various loads which is nearer to the ANN values as shown in Figure 7(d), the error deviation is negligible as shown in Figure 10(d), Mechanical efficiency is almost remains constant for all manifold designs as shown in Figure 10(d).

Atmospheric air head,

$$
\left(\mathrm{h}_{\mathrm{a}}\right)=\mathrm{h}_{\mathrm{w}} \times \frac{\text { density of } \text { water }}{\text { density of air }}
$$

Theoretical volume flow rate of air,

$$
\text { (Qthe) }=\frac{\pi \times d^{2} \times L \times N}{4 \times 60 \times 2} \mathrm{~m}^{3} / \mathrm{s}
$$

where,

d - $0.08 \mathrm{~m}$;

L - Stroke length $0.11 \mathrm{~m}$;

$\mathrm{N}$ - Speed in RPM

Mechanical Efficiency,

$$
\eta_{\text {mech }}=\frac{\text { B.P }}{\text { I.P }} \times 100 \%
$$

\subsubsection{Engine emissions}

Incomplete combustion leads to emission of carbon

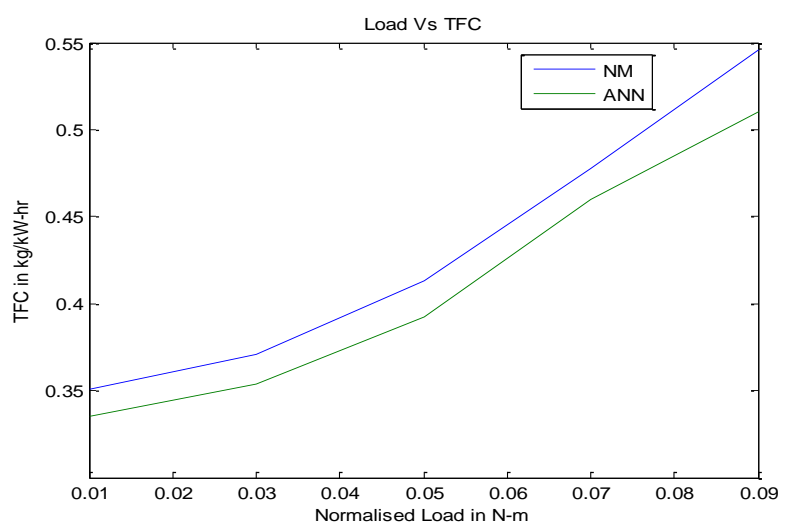

(a)

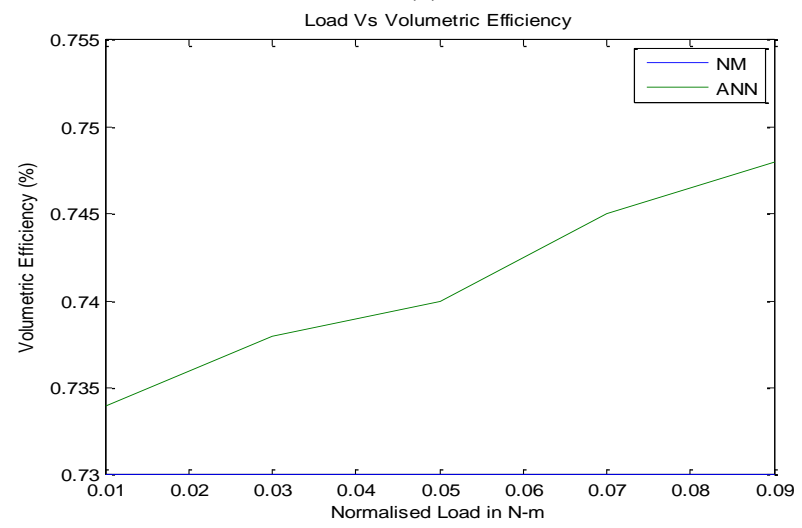

(c) monoxide. It is observed that with increasing load the emission of carbon monoxide also increases because of the high fuel injection during the delay in ignition, this results in incomplete combustion. It is depicted in Figure 8(b), for the same input data the $\mathrm{CO}$ emissions are less for $\mathrm{ANN}$, further error deviation is Positive as shown in Figure 9(e).

Emission of hydrocarbons takes place due to incomplete combustion, or high penetration of the injected spray of fuel, or flame quenching on the walls of the low-temperature cylinder and cylinder walls being wet during the time of ignition delay. Hence, hydrocarbon emission increases slightly with the load of the engine increases with two factors working against one another; higher injected fuel raises the incomplete combustion and on the same time, the inside temperature also increases inside the cylinder that also reduces quenching. This is depicted from Figure 8(a). HC emissions are more in Normal manifold and error deviation is Positive as shown in Figure 9(f).

Diesel is made from hydrogen and carbon atoms. At the time of the combustion, the carbon is combined with the oxygen present in the air for producing carbon dioxide, where the proper mixture of fuel and air decreases the formation of Carbon dioxide. It can be observed from the Figure $8(\mathrm{c}) . \mathrm{CO}_{2}$ emissions are more in Normal manifold and error deviation is positive as shown in Figure $9(\mathrm{~g})$. The quality of oxygen indicates the effective utilization of air which indicates the proper fuel and air mixing, in case oxygen content is more in exhaust is an indication of reduction in CO, HC emissions. From Figure 8(d), it shows that the quantity of oxygen from exhaust is less for normal manifold and the error deviation is negative as shown in Figure 9(h).

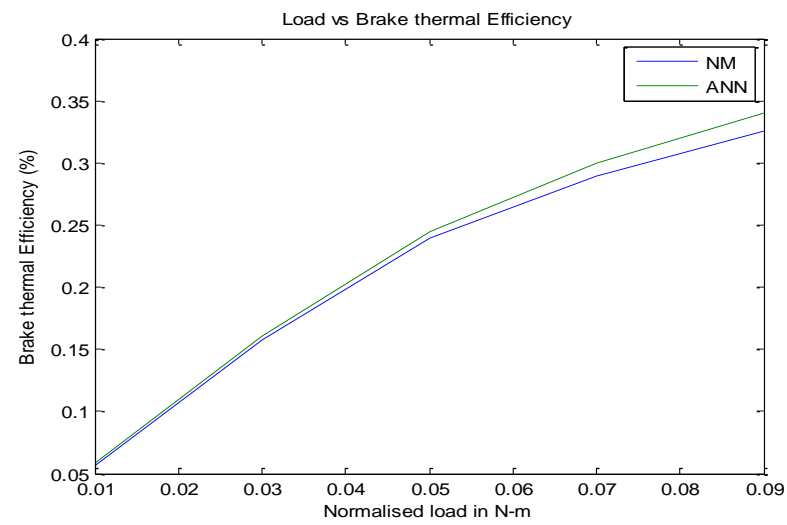

(b)

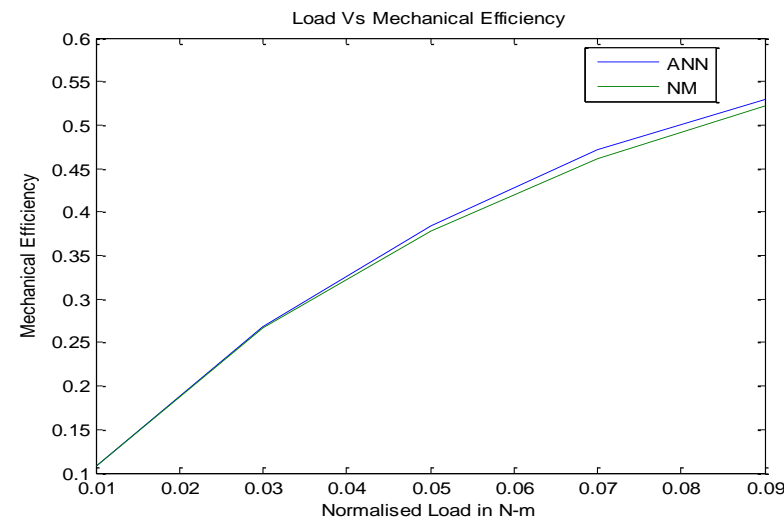

(d)

Figure 7. Comparison of performance parameters between trained data and experimental data 


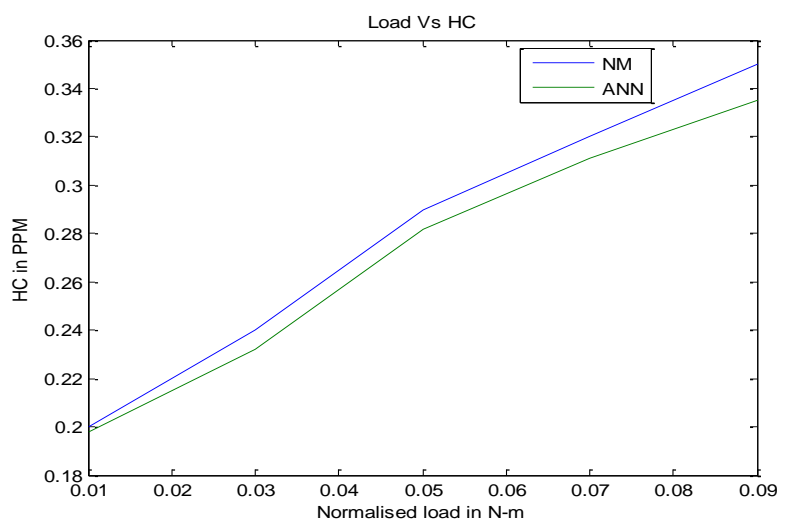

(a)

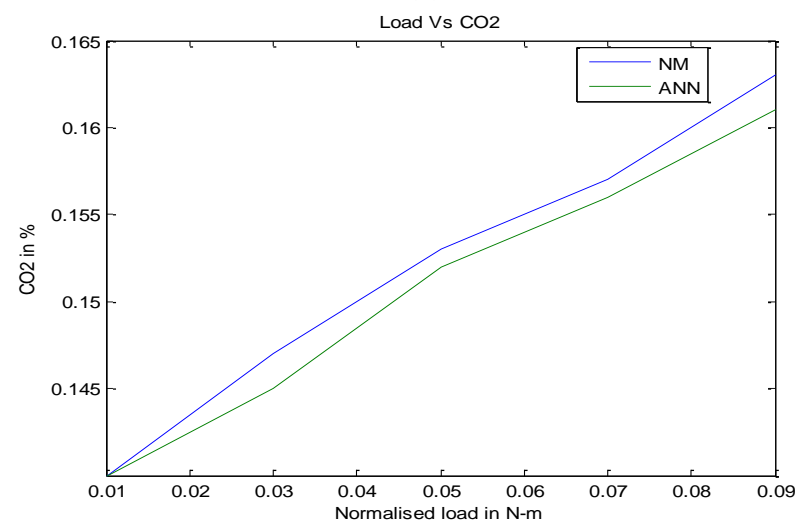

(c)

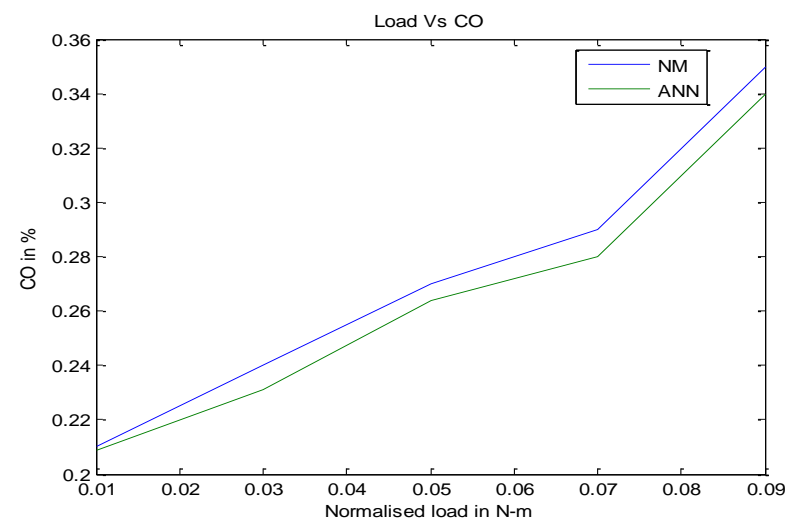

(b)

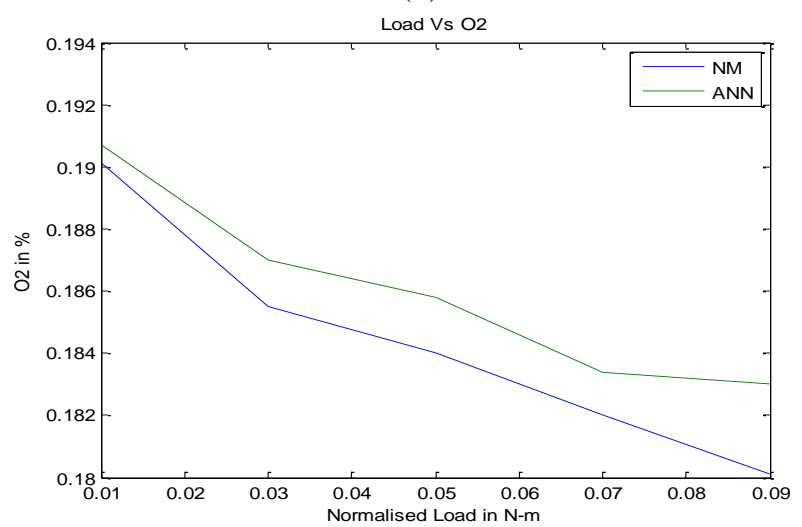

(d)

Figure 8. Comparison of Various emissions between trained values and Experimental values

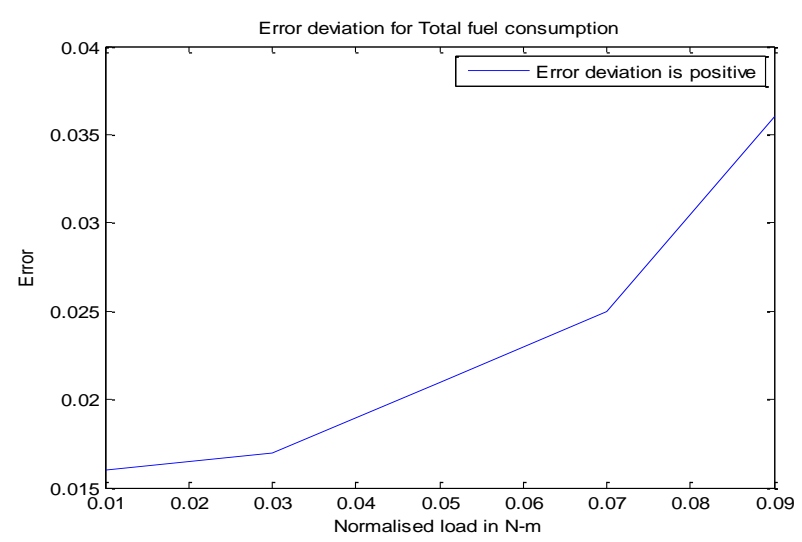

(a)

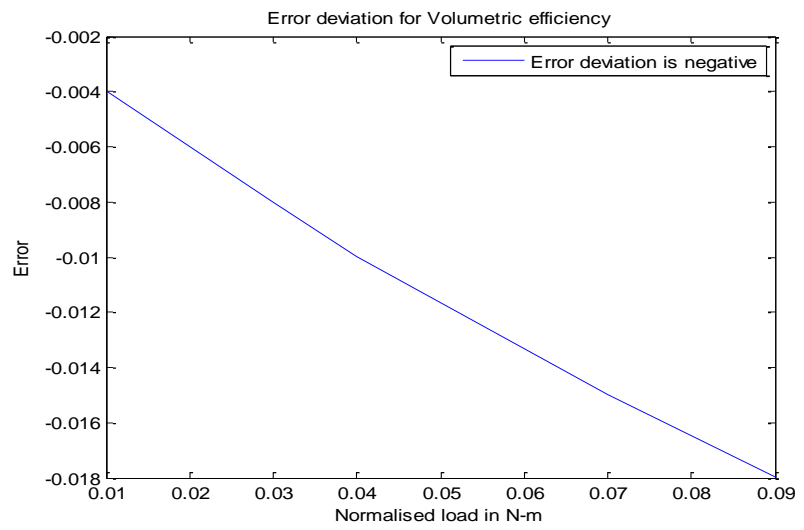

(c)

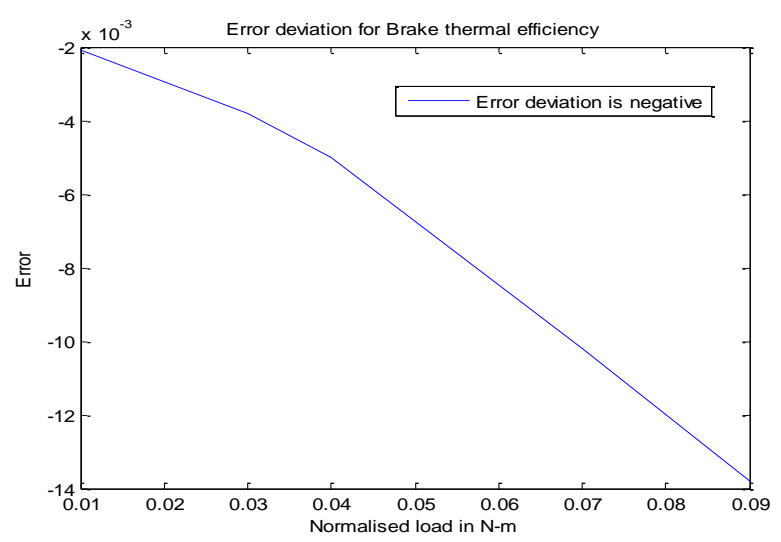

(b)

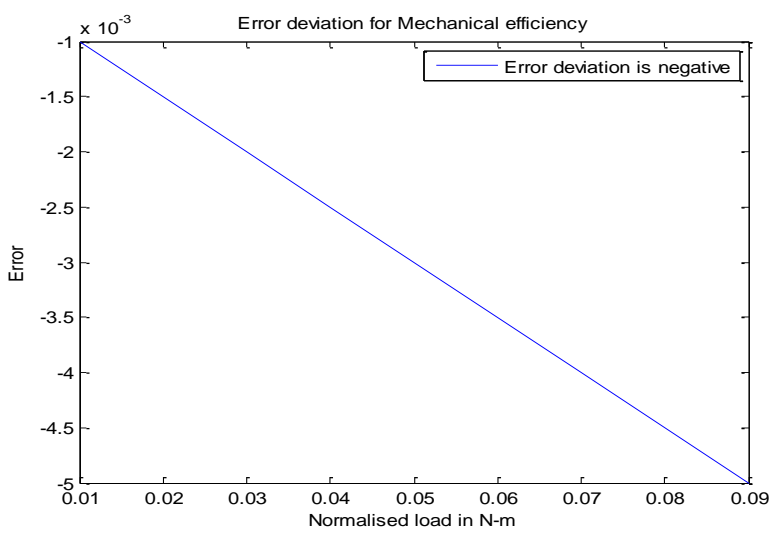

(d) 


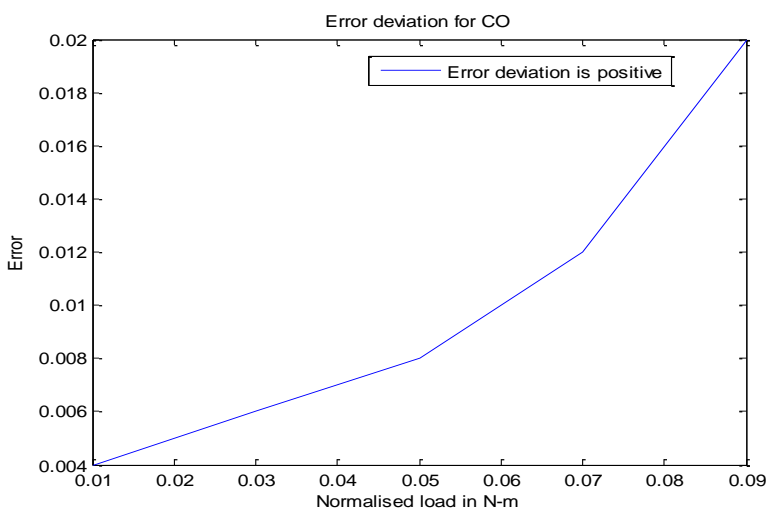

(e)

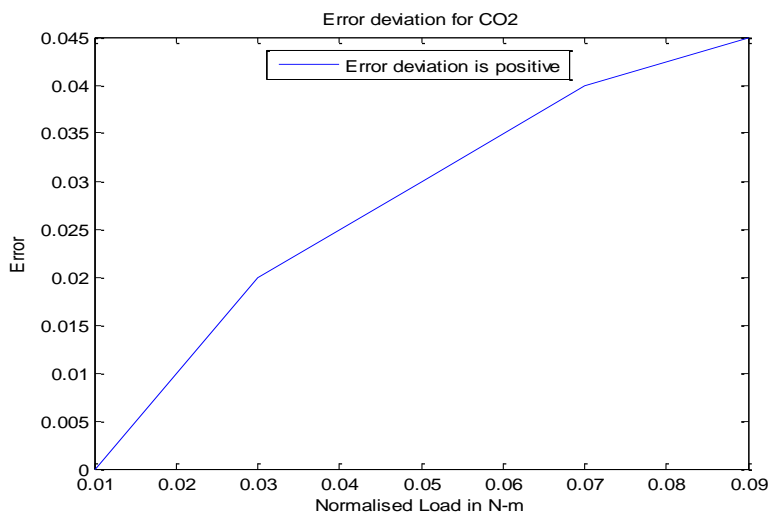

(g)

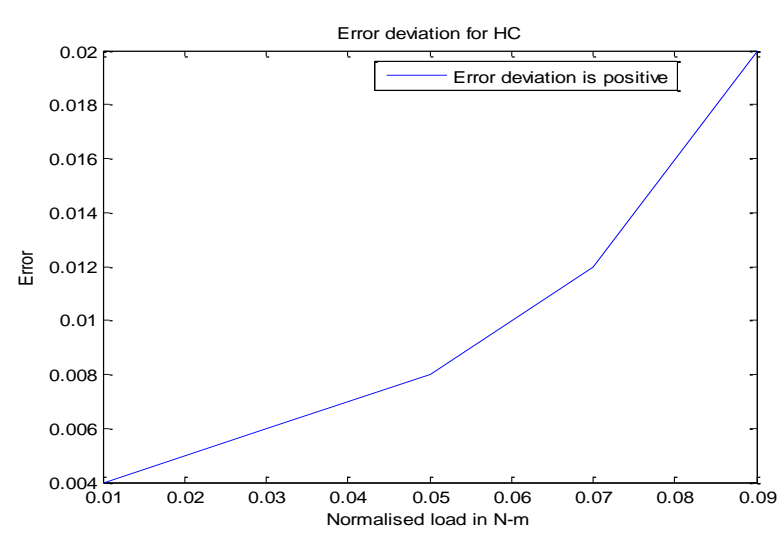

(f)

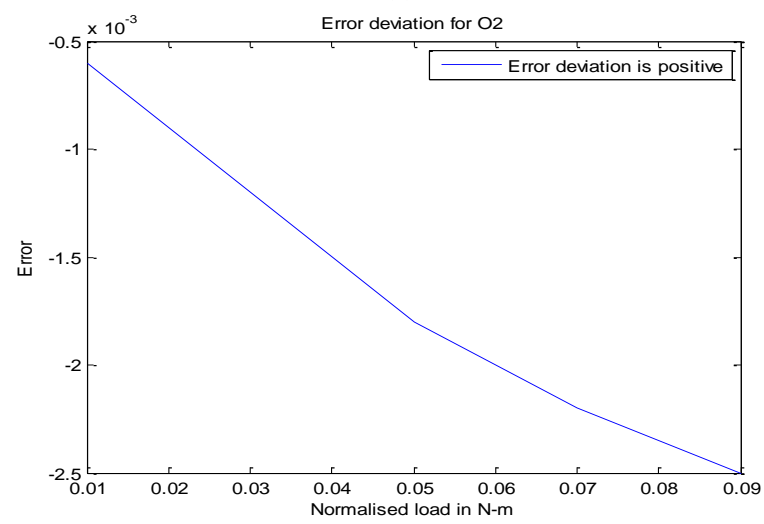

(h)

Figure 9. Error deviation between normal manifold and trained values

The error deviation is more in normal manifold in order to optimize the error deviation manifold designs are changed as shown in Figure 5. Further experimentation is done on the engine by varying manifold design and compared with ANN values.

\subsection{Comparison of ANN values with threaded manifold, manifold with nozzle}

Under this topic the application of proposed method was applied by changing the designs of intake manifolds which provides swirl motion to the air at inlet by enhancing the proper fuel and air mixing which enhances the efficiency and helps reduction of emissions. After experimentation manifold with internal threads are performing far better than manifold and normal manifold where convergent nozzle performance is poor by comparing with normal manifold, ANN values and Threaded manifold as shown in Figure 10, which is due to reduce in the area of cross section at the inlet creating restriction to the air passage as a result sufficient amount of air will not enter inside the engine which leads to consumption of more fuel directly results in decrease in efficiency as observed in Figure 10(a), (c). This also increases emissions due to improper combustion as shown in Figure 11. Due to inadequate supply of air total fuel consumption increases which in turn reduces brake thermal efficiency and also reduces volumetric efficiency as shown in Figure 10(b), (c). Whereas mechanical efficiency remains almost same in all the manifold designs as shown in Figure 10(d). The reason for that is engine is operated at rated speeds and the variation of load in all the designs is same therefore brake power and friction power remain constant for a given set of conditions as a result mechanical efficiency remains constant, by comparing with $\mathrm{ANN}$ values also the error deviation is negligible.

Figure 11(a) depicts Hydrocarbon emission for the tested engines with threaded manifold, Nozzle manifold and ANN values and this is noticed clearly that threaded manifold produces lowest emissions which is due to providing swirl motion to the inlet air that helps in correct fuel and air mixing by reducing emissions, whereas nozzle manifold has more emissions due to restricted flow air so that engine cannot obtained required quantity of air which leads to improper combustion. Similarly, Figure 11(b), (c), (d), shows the HC, $\mathrm{CO}_{2}$ and $\mathrm{O}_{2}$ emissions in these cases also threaded manifolds emissions are less because of proper fuel and air mixing, the oxygen content in the emissions is more which indicates the emissions of $\mathrm{HC}$ and $\mathrm{CO}$ are less whereas for emissions from convergent nozzle is more still it creates swirl motion at entry the quantity of air entered is less as shown in the Figure 6. The error deviation for threaded manifold is compared with trained values as shown in Figure 12. in which error deviation is optimized in threaded manifold with the help of ANN. For threaded manifold TFC is less so that error deviation is negative which indicates fuel consumption is less in threaded manifold, whereas error deviation is positive for brake thermal efficiency and volumetric efficiency which indicates that values obtained from threaded manifold are better than ANN trained values, but for mechanical efficiency error deviation is negative that can be neglected as error deviation is in minimum where as in case of convergent nozzle as shown in Figure 10, the performance parameters are far less than normal manifold so that it is not compared with trained values of ANN. The RMSE values and the MAE values for both the TM and CN over ANN is given in Table 2. The obtained RMSE values are very less compared to [33, 34]. 


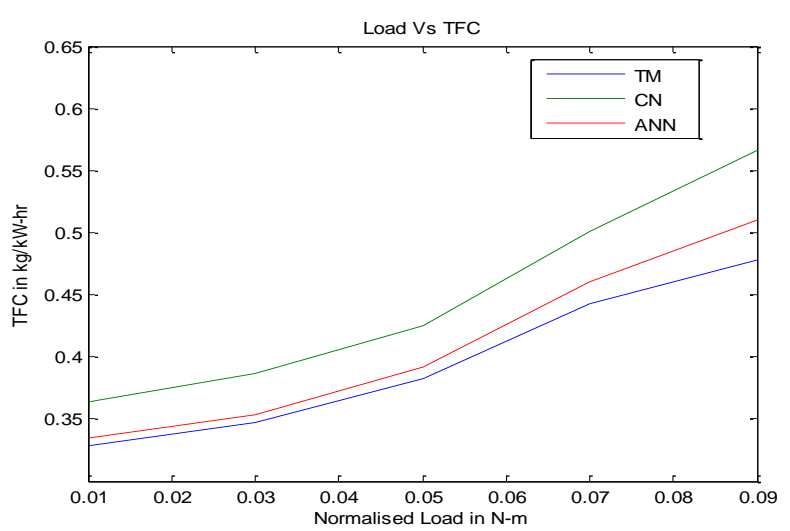

(a)

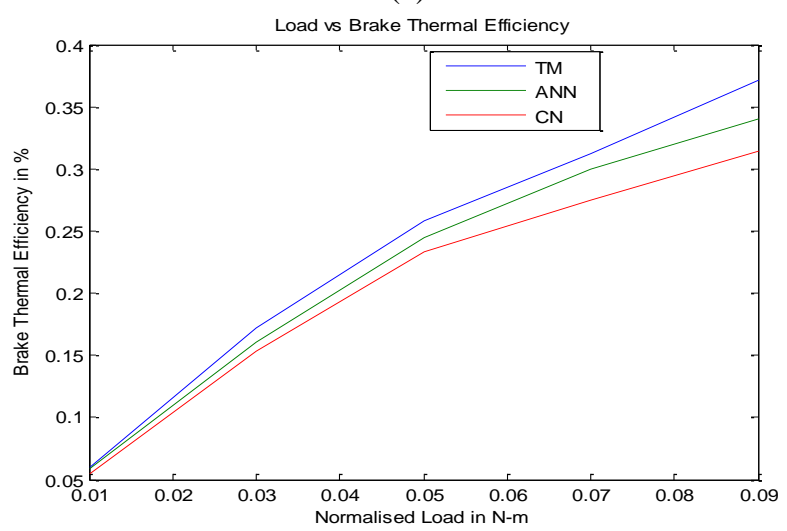

(c)

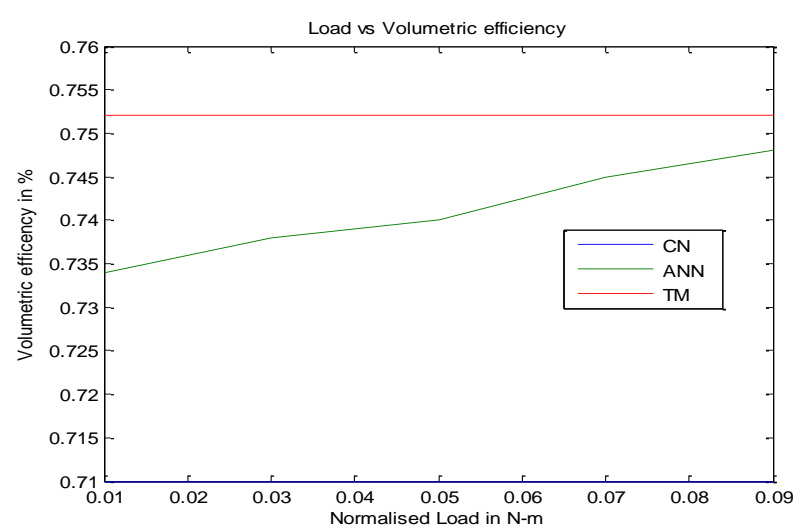

(b)

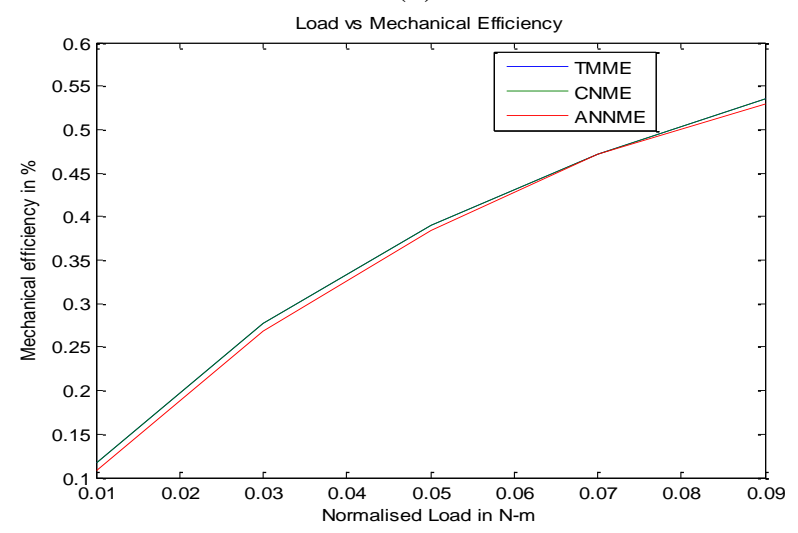

(d)

Figure 10. Comparison of performance parameters between various manifolds and trained values

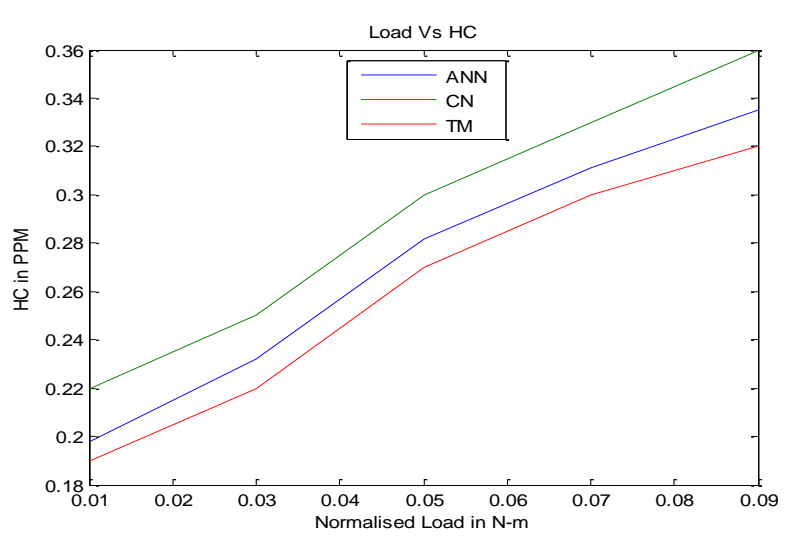

(a)

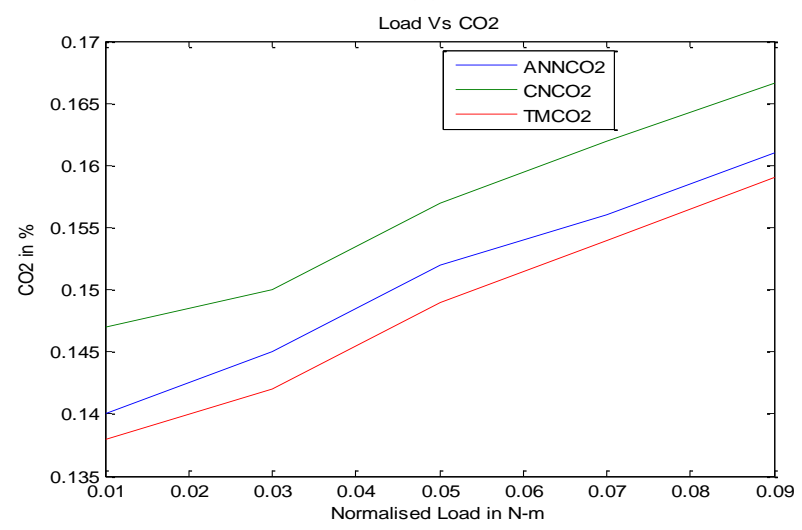

(c)

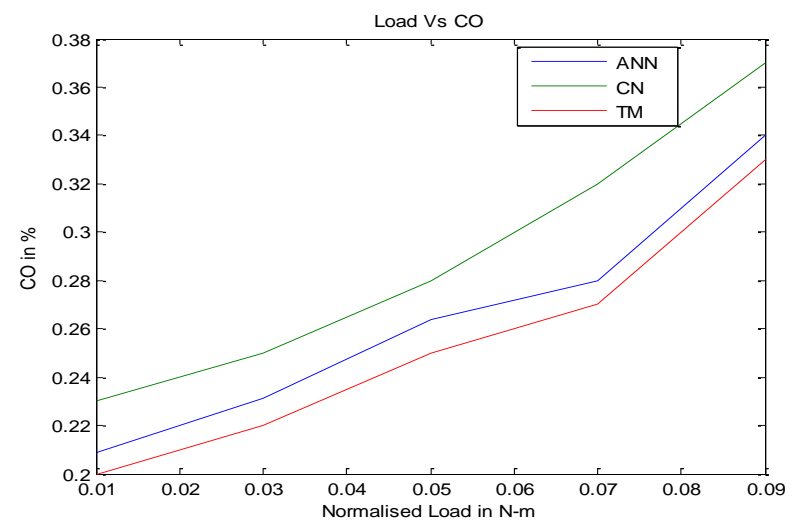

(b)

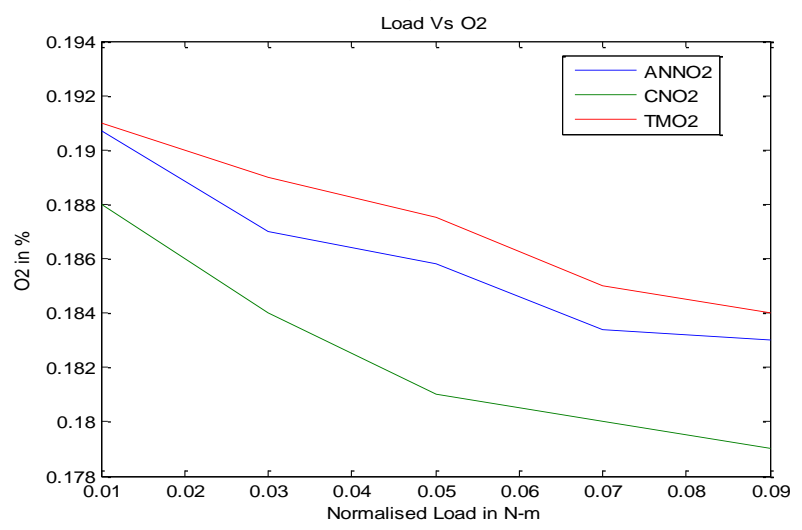

(d)

Figure 11. Comparison of emissions between various manifolds and trained values 


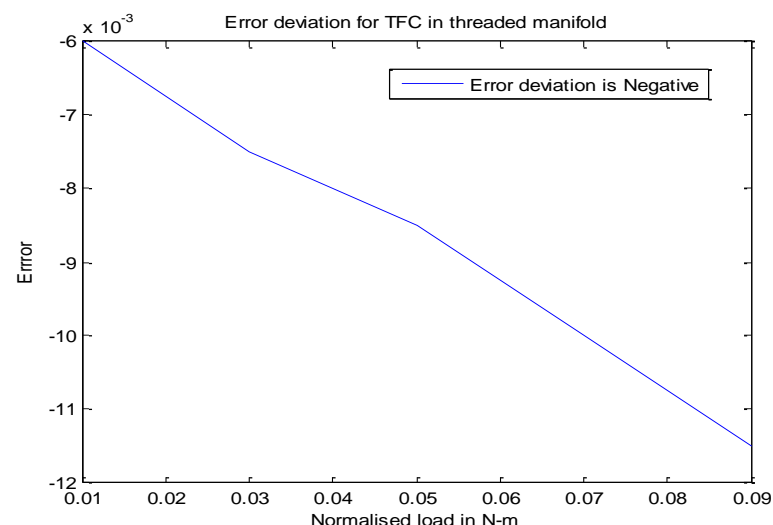

(a)

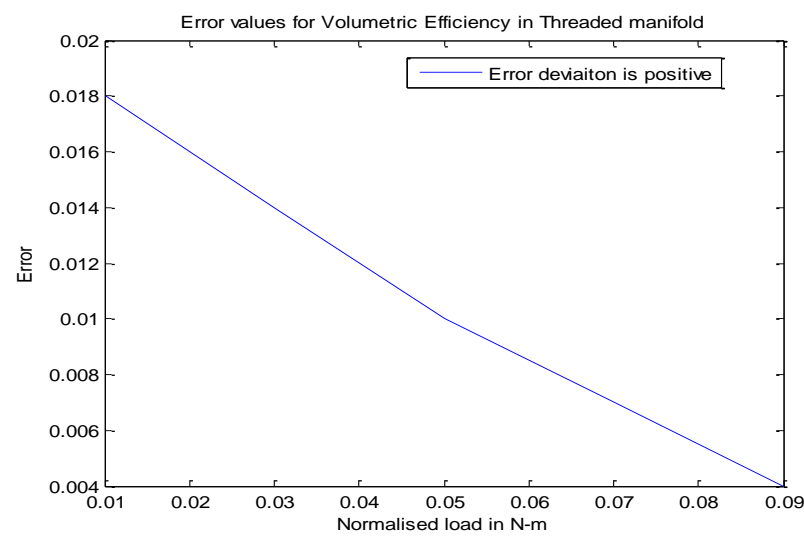

(C)

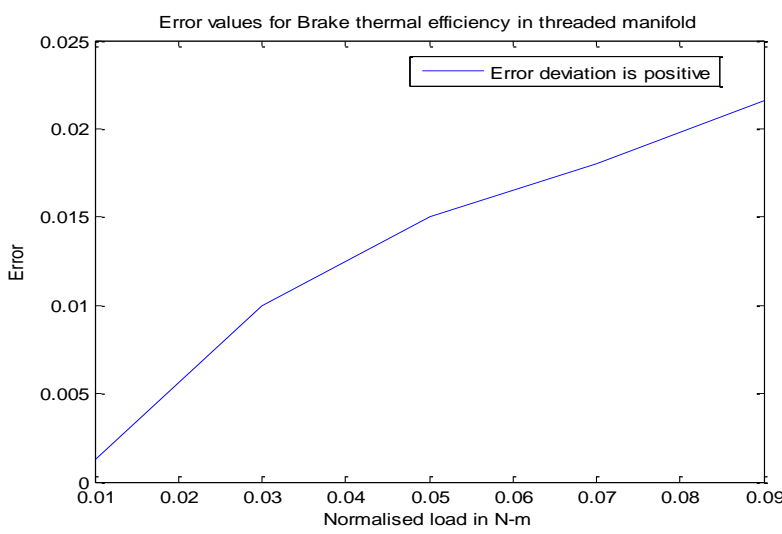

(b)

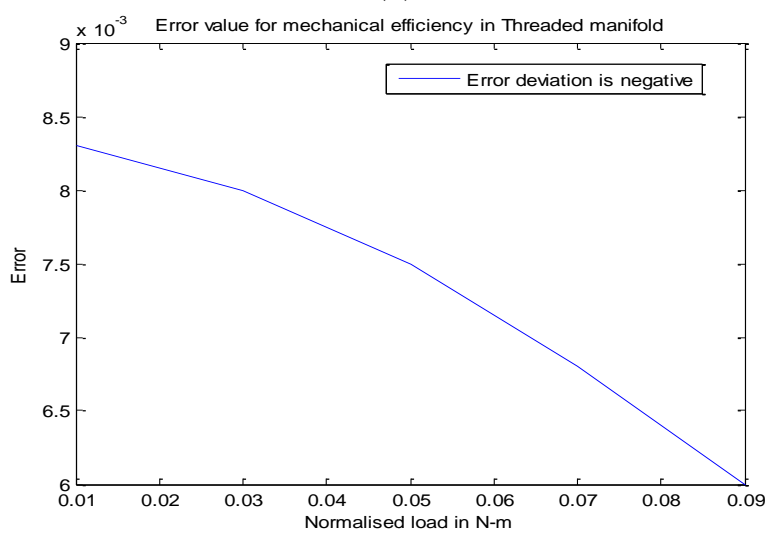

(d)

Figure 12. Error deviation threaded manifold and trained values

Table 2. RMSE and MAE

\begin{tabular}{|c|c|c|c|c|c|c|c|c|c|c|}
\hline \multirow{2}{*}{$\begin{array}{c}\text { Parameters } \\
\text { Load }\end{array}$} & \multicolumn{5}{|c|}{ ANN vs. TM } & \multicolumn{5}{|c|}{ ANN vs. CN } \\
\hline & 0.01 & 0.03 & 0.05 & 0.07 & 0.09 & 0.01 & 0.03 & 0.05 & 0.07 & 0.09 \\
\hline \multicolumn{11}{|c|}{ ROOT MEAN SQUARE ERROR } \\
\hline $\mathrm{BP}$ & $0.01 \%$ & $0.01 \%$ & $0.01 \%$ & $0.01 \%$ & $0.01 \%$ & $0.01 \%$ & $0.01 \%$ & $0.01 \%$ & $0.01 \%$ & $0.01 \%$ \\
\hline TFC & $0.37 \%$ & $0.42 \%$ & $0.58 \%$ & $1.04 \%$ & $1.96 \%$ & $3.92 \%$ & $4.46 \%$ & $4.62 \%$ & $6.06 \%$ & $8.82 \%$ \\
\hline BTE & $0.08 \%$ & $0.66 \%$ & $0.78 \%$ & $0.78 \%$ & $1.94 \%$ & $0.64 \%$ & $1.59 \%$ & $2.25 \%$ & $3.84 \%$ & $5.12 \%$ \\
\hline VE & $1.10 \%$ & $0.86 \%$ & $0.73 \%$ & $0.43 \%$ & $0.24 \%$ & $4.04 \%$ & $4.29 \%$ & $4.41 \%$ & $4.72 \%$ & $4.90 \%$ \\
\hline ME & $0.51 \%$ & $0.49 \%$ & $0.42 \%$ & $0.06 \%$ & $0.43 \%$ & $0.51 \%$ & $0.49 \%$ & $0.42 \%$ & $0.06 \%$ & $0.43 \%$ \\
\hline $\mathrm{CO}_{2}$ & $0.12 \%$ & $0.18 \%$ & $0.18 \%$ & $0.12 \%$ & $0.12 \%$ & $0.98 \%$ & $0.80 \%$ & $0.80 \%$ & $0.86 \%$ & $0.37 \%$ \\
\hline $\mathrm{CO}$ & $0.55 \%$ & $0.73 \%$ & $1.96 \%$ & $2.51 \%$ & $0.61 \%$ & $3.12 \%$ & $3.06 \%$ & $3.92 \%$ & $7.41 \%$ & $4.29 \%$ \\
\hline $\mathrm{HC}$ & $0.49 \%$ & $0.73 \%$ & $0.73 \%$ & $0.67 \%$ & $0.92 \%$ & $4.41 \%$ & $2.94 \%$ & $2.94 \%$ & $3.00 \%$ & $3.98 \%$ \\
\hline $\mathrm{O}_{2}$ & $0.02 \%$ & $0.12 \%$ & $0.10 \%$ & $0.10 \%$ & $0.06 \%$ & $0.26 \%$ & $0.49 \%$ & $0.69 \%$ & $0.51 \%$ & $0.55 \%$ \\
\hline \multicolumn{11}{|c|}{ Mean Absolute Error } \\
\hline$\overline{B P}$ & $1.00 \%$ & $3.00 \%$ & $5.00 \%$ & $7.00 \%$ & $9.00 \%$ & $0.50 \%$ & $1.50 \%$ & $2.50 \%$ & $3.50 \%$ & $4.50 \%$ \\
\hline TFC & $0.01 \%$ & $0.01 \%$ & $0.01 \%$ & $0.01 \%$ & $0.01 \%$ & $0.01 \%$ & $0.00 \%$ & $0.01 \%$ & $0.00 \%$ & $0.01 \%$ \\
\hline BTE & $2.14 \%$ & $2.44 \%$ & $2.60 \%$ & $3.55 \%$ & $5.39 \%$ & $1.96 \%$ & $2.23 \%$ & $2.31 \%$ & $3.03 \%$ & $4.41 \%$ \\
\hline VE & $0.36 \%$ & $1.13 \%$ & $1.52 \%$ & $2.31 \%$ & $3.53 \%$ & $0.32 \%$ & $0.80 \%$ & $1.13 \%$ & $1.92 \%$ & $2.56 \%$ \\
\hline ME & $2.57 \%$ & $2.57 \%$ & $2.57 \%$ & $2.57 \%$ & $2.57 \%$ & $2.02 \%$ & $2.14 \%$ & $2.20 \%$ & $2.36 \%$ & $2.45 \%$ \\
\hline $\mathrm{CO}_{2}$ & $0.51 \%$ & $0.49 \%$ & $0.42 \%$ & $0.06 \%$ & $0.43 \%$ & $0.25 \%$ & $0.24 \%$ & $0.21 \%$ & $0.03 \%$ & $0.21 \%$ \\
\hline $\mathrm{CO}$ & $0.55 \%$ & $0.49 \%$ & $0.49 \%$ & $0.49 \%$ & $0.24 \%$ & $0.49 \%$ & $0.40 \%$ & $0.40 \%$ & $0.43 \%$ & $0.18 \%$ \\
\hline $\mathrm{HC}$ & $1.84 \%$ & $1.90 \%$ & $2.94 \%$ & $4.96 \%$ & $2.45 \%$ & $1.56 \%$ & $1.53 \%$ & $1.96 \%$ & $3.70 \%$ & $2.14 \%$ \\
\hline $\mathrm{O}_{2}$ & $2.45 \%$ & $1.84 \%$ & $1.84 \%$ & $1.84 \%$ & $2.45 \%$ & $2.20 \%$ & $1.47 \%$ & $1.47 \%$ & $1.50 \%$ & $1.99 \%$ \\
\hline
\end{tabular}

\section{CONCLUSION}

ANN was applied for a 4-stroke diesel engine which is used to estimate TFC, Brake thermal Efficiency, Volumetric efficiency, Mechanical Efficiency, $\mathrm{CO}, \mathrm{HC}, \mathrm{CO}_{2}$ and $\mathrm{O}_{2}$ emissions in this study. The input data used in the ANN is obtained from experimental data. The results obtained from ANN is compared with experimental data in which error deviation is more, to reduce error deviation few changes are done to engine inlet manifold and experimentation is done. By comparing the results, the summary of the results of the current work is presented in the following:

(a) Threaded manifold design is tested on the engine which generate swirl for the incoming air, so that proper mixing of air and fuel takes place inside the engine which reduces fuel consumption thereby increasing thermal 
efficiency and volumetric efficiency for all the loads at the same time reduces emissions considerably when compared with normal manifold design and ANN values

(b) Convergent nozzle manifold design is also tested on the engine it also generates swirl for the incoming air but the area of cross section reduces at the inlet of the engine which causes restriction for air flow due to which sufficient amount of oxygen is not present inside the engine increases fuel consumption which leads to improper combustion as a result emission level increases reducing efficiency of engine.

(c) The error variation among the ANN model and the $\mathrm{TM}$ and $\mathrm{CN}$ is very less.

(d) The values of RMSE and MAE among the models of ANN and TM, CN is very less and it shows the conformity of the model to produce accurate prediction on process parameters and emission.

(e) The emission estimated in the CI engine is observed to be in conformity with the emission regulation.

(f) As a result, the use of ANN helps in improving the performance of engine in a sequential approach.

(g) There is a scope for improving the performance of Convergent Nozzle engine by increasing the inlet pressure. These will be helpful for increase in efficiency and reduction in emissions

\section{REFERENCES}

[1] Omidvarborna, H., Kumar, A. (2015). Recent studies on soot modeling for diesel combustion. Renewable and Sustainable Energy Reviews, 48: 635-647. https://doi.org/10.1016/j.rser.2015.04.019

[2] Kapuria, C.V., Rathod, P.P. (2015). Experimental investigation on performance and emission of IC-engine by modifying inlet manifold. International Journal of Advance Engineering and Research Development (IJAERD), 2(6).

[3] Sadiq, A., Elgergawi, M., Bassiony, M., Ahmed, S. (2015). New induction manifold designs for high performance and low emission diesel engine running on alternative fuels. 13t International Energy Conversion Engineering Conference. https://doi.org/10.2514/6.2015-4017

[4] Turkmen, A.C., Demir, U., Cetinkaya, O., Celik, C. (2018). The effect of different intake manifold geometries on single-cylinder diesel engine soot formation and performance. International Journal of Mechanical and Production Engineering, 6(5).

[5] Sadeqa, A.M., Bassiony, M.A., Elbashir, A.M., Khraisheh, M. (2019). Combustion and emissions of a diesel engine utilizing novel intake manifold designs and running on alternative fuels. Fuel, 255: 115769. https://doi.org/10.1016/j.fuel.2019.115769

[6] Manmadhacharya, A., Kumaron M.S., Kumar, Y.R. (2017). Design \& manufacturing of spiral intake manifold to improve volumetric efficiency of injection diesel engine by AM process rise in the volumetric efficiency. Materialstoday: Proceedings, 4(2): 10841090. https://doi.org/10.1016/j.matpr.2017.01.123

[7] Abdul Gafoor, C.P., Gupta, R. (2015). Numerical investigation of piston bowl geometry and swirl ratio on emission from diesel engines. Energy Conversion and Management, 101: 541-551. http://dx.doi.org/10.1016/j.enconman.2015.06.007
[8] Prabhakaran, P., Ramesh, P. (2016). Experimental and numerical investigation of swirl enhancing grooves on the flow and combustion characteristics of a DI diesel engine. Energy, 115: 1234-1245. https://doi.org/10.1016/j.energy.2016.09.063

[9] NagaDeepthi V.V., GovindaRajulu, K. (2019). Development of swirl generation in intake manifold to enhance performance of the engine. International Journal of Scientific \& Engineering Research, 10(6): 587-595. https://doi.org/10.35940/ijitee.K2537.0981119

[10] Kumar, A.R., Raju G.J., Reddy, K.H. (2015). Performance evaluation of a diesel engine in the presence of a convergent nozzle with internal blades in the air intake manifold. International Journal of Innovative Research in Science, Engineering and Technology, https://doi.org/10.15680/IJIRSET.2015.0407192

[11] Satyanarayana, I., Vidyasagar, T. (2016). Performance evaluation of variable compression ratio for diesel engine using convergent-divergent nozzle in the intake manifold. IJISET - International Journal of Innovative Science, Engineering \& Technology, 3(9): 1-5.

[12] Thamaraikanan, R., Anish, M., Kanimozhi, B., George, T., George Koshy, V. (2015). Design and analysis of an intake manifold in an IC engine. Applied Mechanics and Materials, (766-767): 1021-1027. https://doi.org/10.4028/www.scientific.net/amm.766767.1021

[13] Sreedhar T., Rao, B.N. (2020). Computational modeling and analysis of intake taper manifold of an internal combustion engine. In: Satapathy S., Raju K., Molugaram K., Krishnaiah A., Tsihrintzis G. (eds) International Conference on Emerging Trends in Engineering (ICETE). Learning and Analytics in Intelligent Systems, vol 2. Springer, Cham. https://doi.org/10.1007/978-3-030-24314-2_83

[14] Wang. G.X., Yu W.B., Li, X.B., Su, Y.P., Yang, R., Wu, W.T. (2019). Study on dynamic characteristics of intake system and combustion of controllable intake swirl diesel engine. Energy, 180: 1008-1018. https://doi.org/10.1016/j.energy.2019.05.162

[15] Soufi, M.D., Ghobadian, B., Najafi, G., Sabzimaleki, M., Jaliliantabar, F. (2015). Performance and exhaust emissions of a SI two-stroke engine with bio lubricants using artificial neural network. Energy Procedia, 75: 3-9. https://doi.org/10.1016/j.egypro.2015.07.127

[16] Uslu, S., Celik, M.B. (2018). Prediction of engine emissions and performance with artificial neural networks in a single cylinder diesel engine using diethyl ether. Engineering Science and Technology, an International Journal, 21(6): 1194-1201. https://doi.org/10.1016/j.jestch.2018.08.017

[17] Javed, S., Satyanarayana Murthy, Y.V.V., Baig, R.U., Rao, D.P. (2015). Development of ANN model for prediction of performance and emission characteristics of hydrogen dual fueled diesel engine with Jatropha Methyl Ester biodiesel blends. Journal of Natural Gas Science and Engineering, 26: 549-557. https://doi.org/10.1016/j.jngse.2015.06.041

[18] Kurtgoz, Y., Karagoz, M., Deniz, E. (2017). Biogas engine performance estimation using ANN. Engineering Science and Technology, an International Journal, 20(6): 1563-1570. https://doi.org/10.1016/j.jestch.2017.12.010

[19] Ramchandra, R., Pandurangadu, V. (2016). Recent 
developments on diesel engine performance and emissions fuelled with biodiesel-diesel-ethanol blends. IJMETMR, 5(11): 10-15.

[20] Chakraborty, A., Roy, S., Banerjee, R. (2016). An experimental based ANN approach in mapping performance emission characteristics of a diesel engine operating in dual-fuel mode with LPG. Journal of Natural Gas Science and Engineering, 28: 15-30. https://doi.org/10.1016/j.jngse.2015.11.024

[21] Boruah, D., Thakur, P.K., Baruah, D. (2016). Artificial neural network-based modeling of internal combustion engine performance. International Journal of Engineering Research \& Technology (IJERT), 5(3): 568-576.

[22] Rao, K.P., Babu, T.V., Anuradha, G., Rao, B.V.A. (2016). IDI diesel engine performance and exhaust emission analysis using biodiesel with an artificial neural network (ANN). Egyptian Journal of Petroleum, 26(3):

593-600. http://dx.doi.org/10.1016/j.ejpe.2016.08.006

[23] Turkson, R.F., Yan, F.W., Ahmed Ali, M.K., He, J. (2016). Artificial neural network applications in the calibration of spark-ignition engines: Anoverview. Engineering Science and Technology, an International Journal, 19(3): 1346-1359. http://dx.doi.org/10.1016/j.jestch.2016.03.003

[24] Çelebi, K., Uludamar, E., Tosun, E., Yıldızhan, S., Aydın, K., Özcanlı, M. (2017). Experimental and artificial neural network approach of noise and vibration characteristic of an unmodified diesel engine fuelled with conventional diesel, and biodiesel blends with natural gas addition. Fuel, 197: 159-173. https://doi.org/10.1016/j.fuel.2017.01.113

[25] Gürgen, S., Ünver, B., Altin, I. (2018). Prediction of cyclic variability in a diesel engine fueled with nbutanol and diesel fuel blends using artificial neural network. Renewable Energy, 117: 538-544. https://doi.org/10.1016/j.renene.2017.10.101

[26] Anarghya, A., Rao, N., Nayak, N., Tirpude, A.R., Harshith, D.N., Samarth, B.R. (2018). Optimized ANNGA and experimental analysis of the performance and combustion characteristics of HCCI engine. Applied Thermal Engineering, 132: 841-868. https://doi.org/10.1016/j.applthermaleng.2017.12.129

[27] Channapattana S.V., Pawar A.A., Kamble, P.G. (2017). Optimisation of operating parameters of DI-CI engine fueled with second generation Bio-fuel and development of ANN based prediction model. Applied Energy, 187: 84-95. https://doi.org/10.1016/j.apenergy.2016.11.030

[28] Domínguez-Saez, A., Ratta, G.A., Barrios, C.C. (2018). Prediction of exhaust emission in transient conditions of a diesel engine fueled with animal fat using artificial neural network and symbolic regression. Energy, 149: 675-683. https://doi.org/10.1016/j.energy.2018.02.080

[29] Leo, G.M.L, Sekar, S., Arivazhagan, S. (2018). Experimental investigation, optimization and ANN model prediction of a gasoline premixed waste cooking oil fueled HCCI-DI engine. J Braz. Soc. Mech. Sci. Eng, 40: 49. https://doi.org/10.1007/s40430-018-0967-1

[30] Mehra, R.K., Duan, H., Luo, S.J., Rao, A., Ma, F.H. (2018). Experimental and artificial neural network (ANN) study of hydrogen enriched compressed natural gas $(\mathrm{HCNG})$ engine under various ignition timings and excess air ratios. Applied Energy, 228: 736-754. https://doi.org/10.1016/j.apenergy.2018.06.085

[31] Nola, F., Giardiello, G., Gimelli, A., Molteni, A., Muccillo, M., Picariello, R. (2019). Volumetric efficiency estimation based on neural networks to reduce the experimental effort in engine base calibration. Fuel, 244: 31-39. https://doi.org/10.1016/j.fuel.2019.01.182

[32] Korkut I., Acir A., Boy, M. (2011). Application of regression and artificial neural network analysis in modeling of tool-chip interface temperature in machining. Expert Syst. Appl., 38(9): 11651-11656. https://doi.org/10.1016/j.eswa.2011.03.044

[33] Roy, S., Banerjee, R., Bose, P.K. (2014). Performance and exhaust emissions prediction of a CRDI assisted single cylinder diesel engine coupled with EGR using artificial neural network. Applied Energy, 119:330-340. https://doi.org/10.1016/j.apenergy.2014.01.044

[34] Chakraborty, A., Roy, S., Banerjee, R. (2016). An experimental based ANN approach in mapping performance-emission characteristics of a diesel engine operating in dual-fuel mode with LPG. Journal of Natural Gas Science and Engineering, 28: 15-30. https://doi.org/10.1016/j.jngse.2015.11.024

\section{NOMENCLATURE}

$\begin{array}{ll}\mathrm{CO}_{2} & \text { Carbon Dioxide } \\ \mathrm{CO} & \text { Carbon Monoxide } \\ \mathrm{HC} & \text { Hydro Carbons } \\ \mathrm{O}_{2} & \text { Oxygen } \\ \mathrm{ANN} & \text { Artificial Neural Network } \\ \mathrm{NM} & \text { Normal Manifold } \\ \mathrm{TM} & \text { Threaded Manifold } \\ \mathrm{CN} & \text { Convergent Nozzle } \\ \mathrm{CI} & \text { Compression Ignition } \\ \text { TKE } & \text { Turbulent Kinetic Energy } \\ \text { TFC } & \text { Total Fuel Consumption } \\ \mathrm{BTH} & \text { Brake Thermal Efficiency } \\ \text { VE } & \text { Volumetric Efficiency } \\ \mathrm{ME} & \text { Mechanical Efficiency }\end{array}$

